\title{
In-Situ Alumina/Aluminate Platelet Composites
}

\author{
Pei-Lin Chen ${ }^{\star}$ and I-Wei Chen ${ }^{\star}$
}

Department of Materials Science and Engineering, University of Michigan, Ann Arbor, Michigan $48109-2136$

\begin{abstract}
Alumina composites containing in-situ-formed hexaluminate $\left(\mathrm{LaAl}_{11} \mathrm{O}_{18}, \mathrm{LaMgAl}_{11} \mathrm{O}_{19}, \mathrm{SrAl}_{12} \mathrm{O}_{19}\right.$, and $\mathrm{Mg}_{2} \mathrm{NaAl}_{15} \mathrm{O}_{25}$ ) platelets can be pressureless-sintered to high density. The grain morphology of the aluminates can be controlled by composition. A peak toughness $50 \%$ higher than that of alumina is obtained at 30 vol\% aluminates, with a modest reduction (10\%) in hardness and Young's modulus. Although crack-bridging by aluminate platelets is apparently operating, the maximum toughness is intrinsically limited by the low cohesive strength of these layer compounds.
\end{abstract}

\section{Introduction}

NTHE last decade ceramists have pursued microstructural toughening through use of a second phase with a high aspect ratio (whiskers, fibers, and platelets). These composites are difficult to sinter to high density, however, because of the constraint of the second-phase network, and they must be hotpressed in most cases. Ideally, if the microstructural features are developed after densification is first completed, via in-situ formation of a second phase which has a highly anisotropic growth habit, then a tough ceramic composite can be obtained without the sintering difficulty. For example, Hori et al. ${ }^{\prime}$ reported an in-situ composite of $\mathrm{TiO}_{2}$ matrix with dispersed corundum platelets whose anisotropic growth was promoted by sodium doping. Toughness of up to $7 \mathrm{MPa} \cdot \mathrm{m}^{1 / 2}$ was obtained. In another case, in-situ formation of elongated, rodlike grains in $\mathrm{Si}_{3} \mathrm{~N}_{4}$ sintered under a nitrogen-gas overpressure, resulted in self-reinforcement with an improved toughness in excess of $10 \mathrm{MPa} \cdot \mathrm{m}^{1 / 2}$. $^{2}$ In both examples, high density could readily be achieved. Successful toughness enhancement was also reported for $3 \mathrm{Y}-\mathrm{TZP} / \mathrm{mullite}$ composites in which elongated mullite grains could be formed in situ, ${ }^{3}$ although much of the mullite effect, in our opinion, seemed to be attributable to the larger grain size in the composite which facilitates transformation toughening.

To adopt the above alloy development concept for use in the $\mathrm{Al}_{2} \mathrm{O}_{3}$ system, we first searched for a compatible second phase with an anisotropic growth habit. $\mathrm{Al}_{2} \mathrm{O}_{3}$ is compatible with many layer aluminate compounds such as $\mathrm{LaAl}_{11} \mathrm{O}_{18}$ (with $\beta$-alumina structure) and $\mathrm{LaMgAI} \mathrm{O}_{11} \mathrm{O}_{19}$ (with magnetoplumbite structure), as well as others in the same structural family. These aluminates may be termed hexaluminates in analogy to the similar structural family of hexaferrite. They are composed of spinel blocks separated by layers of cations and oxygen ions. Such compounds are highly stable and anisotropic, and may be well suited for toughening reinforcements. Indeed, by incorporating these phases into transformation-toughened $\mathrm{ZrO}_{2}$, favorable

\footnotetext{
D. K. Shetty-contributing cditor
}

Manuscript No. 196026. Received January 29, 1992; approved June 17, 1992 Presented at the 93rd Annual Meeting of the American Ceramic Society, Cincinnati, OH, May 2, 1991 (Ceramic Matrix Composites Symposium, Paper No 111-SVI-91).

Supported by the U.S. Department of Energy (BES) under Grant No. DE-FG02-87ER45302

*Member, American Ceramic Socicty. results have been reported. Tsukuma and Takahata added a small amount of $\mathrm{La}_{2} \mathrm{O}_{3}$ to $2 \mathrm{Y}-\mathrm{TZP} / \mathrm{Al}_{2} \mathrm{O}_{3}$ to form $\mathrm{LaAl}{ }_{11} \mathrm{O}_{18}$ platelets. ${ }^{4}$ The resultant composite had a higher fracture toughness and higher strength at high temperatures as compared to the base $2 \mathrm{Y}-\mathrm{TZP} / \mathrm{Al}_{2} \mathrm{O}_{3}$. Cutler et al. ${ }^{5}$ used $\mathrm{SrO}$ as the additive in forming in-situ platelets of $\mathrm{SrAl}_{12} \mathrm{O}_{19}$ in Ce-TZP to obtain an attractive combination of high levels of strength, toughness, and hardness. The present report is an account of the $\mathrm{Al}_{2} \mathrm{O}_{3}$ / $\left(\mathrm{LaAl}_{11} \mathrm{O}_{18}, \mathrm{LaMgAl}_{11} \mathrm{O}_{19}, \mathrm{SrAl}_{12} \mathrm{O}_{19}, \mathrm{Mg}_{2} \mathrm{NaAl}_{15} \mathrm{O}_{25}\right.$ ) system in which the benefits and limitations of in-situ-formed aluminate platelet composites are examined

\section{Experimental Procedure}

\section{(l) Composition}

$\mathrm{Al}_{2} \mathrm{O}_{3}, \mathrm{LaAl}_{11} \mathrm{O}_{18}$, and $\mathrm{LaMgAl} \mathrm{I}_{11} \mathrm{O}_{14}$ form a compatibility triangle which we systematically investigated, especially along the $\mathrm{Al}_{2} \mathrm{O}_{3} / \mathrm{LaAl}_{11} \mathrm{O}_{18}$ and the $\mathrm{Al}_{2} \mathrm{O}_{3} / \mathrm{LaMgAl} \mathrm{MI}_{11} \mathrm{O}_{19}$ binaries. $\mathrm{MgO}$ at $0.1 \mathrm{wt} \%$ was added as a sintering aid to nearly all the specimens in this group. In an attempt to control phase morphology and/or size, as well as their interface characteristics, dopants at $1 \mathrm{wt} \%$ were added to 70 vol\% $\mathrm{Al}_{2} \mathrm{O}_{3} / 30$ vol\% $\mathrm{LaAl}_{11} \mathrm{O}_{18}$. These dopants were chosen to cover a range of ionic charge and size or to provide a glassy liquid. They included $\mathrm{Li}^{+}, \mathrm{Na}^{+}, \mathrm{Mn}^{2+}$, $\mathrm{Sr}^{2+}, \mathrm{Sc}^{3+}, \mathrm{Y}^{3+}, \mathrm{Zr}^{4+}$, and $\mathrm{Si}^{4+}$, some in pairs. Additionally, the composites of $\mathrm{Al}_{2} \mathrm{O}_{3}$ and two other aluminates $\left(\mathrm{NaMg}_{2} \mathrm{Al}_{15} \mathrm{O}_{25}\right.$ and $\left.\mathrm{SrAl}_{12} \mathrm{O}_{19}\right)$ at 30 vol\% were investigated.

\section{(2) Sample Preparation and Testing Procedure}

Commercially available high-purity $(>99.99 \%) \mathrm{Al}_{2} \mathrm{O}_{3}$ powder (AKP-50, Sumitomo Chemical America), and nitrate or carbonate powders were used as starting materials. $\mathrm{SiO}_{2}$ and $\mathrm{ZrO}_{2}$ in the form of oxides were directly used. The nitrate or carbonate powders were dissolved in water or acid, then added to a well-dispersed $\mathrm{Al}_{2} \mathrm{O}_{3}$ slurry, and the $\mathrm{pH}$ of the mixture was adjusted to prevent flocculation. The slurry was dried, and powders were obtained after calcination at $750^{\circ} \mathrm{C}$ for $2 \mathrm{~h}$. The calcined powders were dispersed by attrition milling before casting into cakes by pressure filtration. The dried cakes were isostatically pressed and sintered in air from $1550^{\circ}$ to $1650^{\circ} \mathrm{C}$ for times up to $3 \mathrm{~h}$.

The density of the sintered materials was determined by the water displacement method. Microstructural examination and phase identification were performed by standard scanning electron microscopy (SEM) and X-ray diffraction (XRD) methods. Grain sizes were determined using the average linear intercept length of at least 500 grains. Hardness and fracture toughness were measured by using a Vickers diamond indenter in a universal hardness-testing machine. In addition, average elastic constants were measured by a pulse-echo technique using ultrasound.

\section{Results and Discussion}

All the samples prepared in this study, including the aluminates themselves and composites of various phase assemblages, were better than $99 \%$ of their theoretical density. The phases identified by XRD are corundum for $\mathrm{Al}_{2} \mathrm{O}_{3}, \beta-\mathrm{Al}_{2} \mathrm{O}_{3}$ for $\mathrm{LaAl}_{11} \mathrm{O}_{18}$, magnetoplumbite for $\mathrm{LaMgAl} \mathrm{I}_{11} \mathrm{O}_{19}$, and $\mathrm{SrAl}_{12} \mathrm{O}_{19}$ 

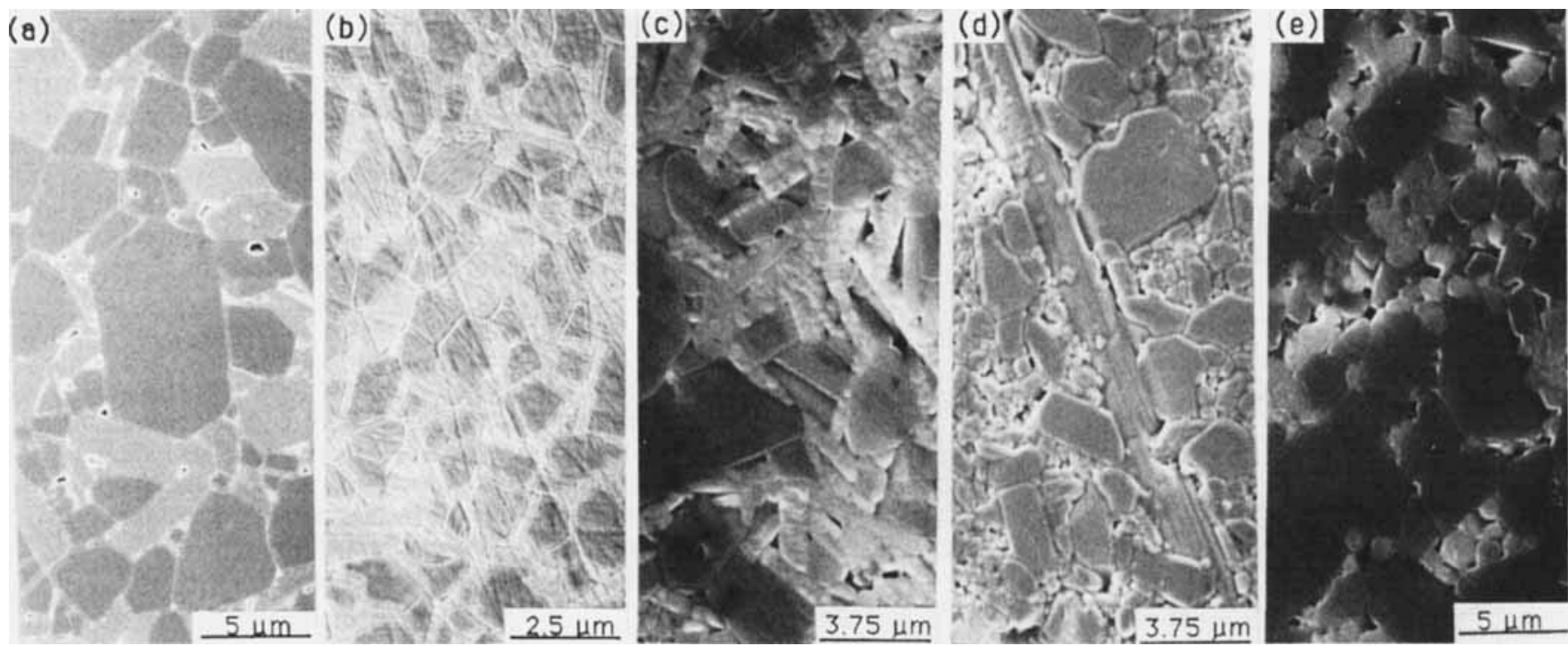

Fig. 1. Microstructures of composites (30 vol\% aluminate/70 vol\% $\mathrm{Al}_{2} \mathrm{O}_{3}$ ): (a) $\mathrm{LaAl}_{11} \mathrm{O}_{18}$, (b) $\mathrm{LaMgAl}_{11} \mathrm{O}_{14},\left(\right.$ c) $\mathrm{SrAl}_{11} \mathrm{O}_{14}$, (d) $\mathrm{Mg}_{2} \mathrm{NaAl}_{15} \mathrm{O}_{25}$, and (e) $\mathrm{MgO}-\mathrm{SiO}_{2}-\mathrm{Na}_{2} \mathrm{O}$-doped 30 vol\% $\mathrm{LaAl}_{11} \mathrm{O}_{18} / 70$ vol\% $\mathrm{Al}_{2} \mathrm{O}_{3}$

and $\beta^{\prime \prime \prime}-\mathrm{Al}_{2} \mathrm{O}_{3}$ for $\mathrm{Mg}_{2} \mathrm{NaAl}_{15} \mathrm{O}_{25}$, as predicted from their compositions and phase relations.

Generally, the aspect ratio of aluminates increases in the following order: $\mathrm{LaAl}_{11} \mathrm{O}_{18}, \mathrm{LaMgAl}_{11} \mathrm{O}_{19}, \mathrm{SrAl}_{12} \mathrm{O}_{19}$, and $\mathrm{Mg}_{2} \mathrm{NaAl}_{15} \mathrm{O}_{25}$. This is shown in Figs. 1(a) to (d) which compare microstructures of four composites with $30 \%$ aluminate phase each. (The aluminate appears as the whiter phase in Figs. 1 (a) to (c) and is due to the heavy element lanthanum or strontium. It has little contrast in Fig. I(d) but can be easily recognized by its elongated shape.) In the case of $\mathrm{LaAl}_{11} \mathrm{O}_{18}$, we further found that the aspect ratio and the particle size were dopant dependent. When $\mathrm{Mg}, \mathrm{Sr}-\mathrm{Mg}, \mathrm{Sc}-\mathrm{Mg}, \mathrm{Y}-\mathrm{Mg}, \mathrm{Sr}-\mathrm{Mg}$, and $\mathrm{Zr}-\mathrm{Mg}$ were used, elongated aluminate grains were found. However, when dopants $\mathrm{Mn}-\mathrm{Mg}, \mathrm{Li}-\mathrm{Mg}, \mathrm{Li}-\mathrm{Si}-\mathrm{Mg}$, and $\mathrm{Na}-$ $\mathrm{Si}-\mathrm{Mg}$ were added, aluminate grains became more equiaxed, as shown in Fig. 1(e). In general, as the amount of the phase (either $\mathrm{Al}_{2} \mathrm{O}_{3}$ or aluminate) decreases, its grain size (or particle size) and aspect ratio decrease. This microstructure refinement is less drastic for $\mathrm{Al}_{2} \mathrm{O}_{3}$ than for aluminates. For $\mathrm{LaAl}_{11} \mathrm{O}_{18}$ and $\mathrm{LaMgAl} \mathrm{Al}_{11} \mathrm{O}_{19}$, a minimum of about $\sim 25 \mathrm{vol} \%$ is required for the development of an elongated morphology. This requirement is probably due to phase connectivity consideration and is apparently less stringent for $\mathrm{NaMg}_{2} \mathrm{Al}_{15} \mathrm{O}_{25}$, which forms highaspect-ratio platelets even at low volume fractions.

Hardness and Young's modulus of aluminates is much lower than that of corundum, and the composite properties follow a

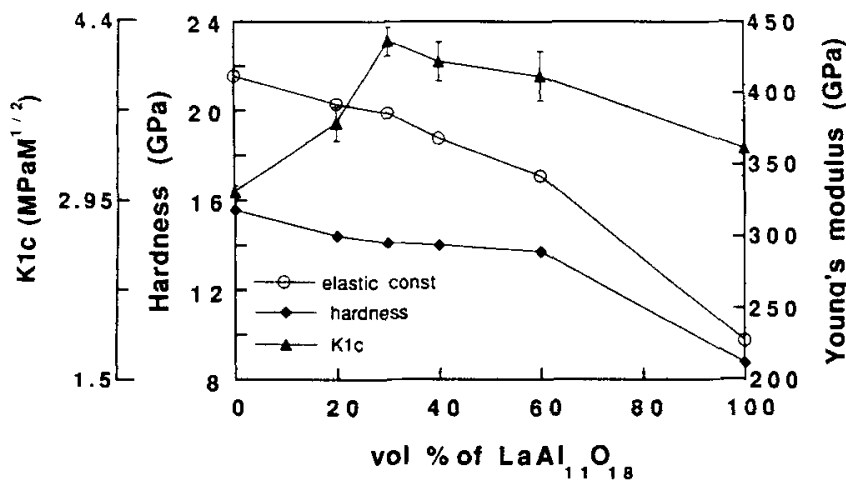

Fig. 2. Hardness, Young's modulus, and fracture toughness versus volume fraction of $\mathrm{LaAl}_{11} \mathrm{O}_{18}$ in $\mathrm{MgO}$-doped $\mathrm{Al}_{2} \mathrm{O}_{3} / \mathrm{LaAl}_{11} \mathrm{O}_{18}$ composites monotonic trend. This is shown in Fig. 2 for the $\mathrm{Al}_{2} \mathrm{O}_{3} /$ $\mathrm{LaAl}_{11} \mathrm{O}_{18}$ binary. The difference in these properties is $\sim 45 \%$ between end members.

Despite their lower hardness and Young's modulus, the aluminates have a slightly higher toughness than corundum. Moreover, the fracture toughness of the composites reaches a peak at an intermediate aluminate fraction of $30 \mathrm{vol} \%$, as shown in Fig. 2. The increment of the toughness over the base line between end members is about $40 \%$, or $50 \%$ if compared with the toughness of $\mathrm{Al}_{2} \mathrm{O}_{3}$. We have not found much difference between various composites regarding the toughness values at this volume fraction. For example, $\mathrm{LaMgAl}_{11} \mathrm{O}_{19}$ has a Young's modulus of $215.4 \mathrm{GPa}$, a hardness of $8.5 \mathrm{GPa}$, and a toughness of $3.2 \mathrm{MPa} \cdot \mathrm{m}^{1 / 2}$; its composite at $30 \mathrm{vol} \%$ has a toughness of $4.3 \mathrm{MPa} \cdot \mathrm{m}^{1 / 2}$. At the latter volume fraction, the toughness values measured for other composites are $4.4 \mathrm{MPa} \cdot \mathrm{m}^{1 / 2}$ for $\mathrm{SrAl}_{12} \mathrm{O}_{19}$ and $4.5 \mathrm{MPa} \cdot \mathrm{m}^{1 / 2}$ for $\mathrm{Mg}_{2} \mathrm{NaAl}_{15} \mathrm{O}_{25}$

Fractography in Fig. 3(a) reveals that, at peak toughness, a crack propagates through $\mathrm{Al}_{2} \mathrm{O}_{3}$ grains $(\mathrm{A})$, aluminate platelets (B), along $\mathrm{Al}_{2} \mathrm{O}_{3}$ grain boundaries (C), and along phase interfaces (D). At a higher volume fraction of aluminates, crack bridging by aluminate ligaments was quite frequently observed, but transgranular fracture was rare. The comparison is shown in Fig. 3.

The toughness increase cannot be due to the variation of the corundum grain size, which decreases monotonically with the addition of aluminates. Indeed, it is well documented that the toughness of $\mathrm{Al}_{2} \mathrm{O}_{3}$ increases with increasing grain size up to a critical grain size, which is beyond the range of this study. Thus, it seems reasonable to attribute the toughening effect to crack-bridging processes similar to those observed in $\mathrm{SiC}$ whisker-reinforced $\mathrm{Al}_{2} \mathrm{O}_{3}$. The increased toughness in our case, however, is modest compared to that reported for SiC-whisker reinforcement, for which a peak toughness of up to $9 \mathrm{MPa} \cdot \mathrm{m}^{1 / 2}$ at $30 \mathrm{vol} \%$ has been reported. ${ }^{6}$

Toughening by whisker reinforcements can be expressed by the energy dissipation $\Delta J$ as

$$
\Delta J=V r \sigma_{\mathrm{f}}^{3} / 6 E \tau
$$

where $V$ is the volume fraction of the whisker, $r$ the whisker radius, $\sigma_{\mathrm{f}}$ the whisker fracture stress, $E$ the Young's modulus of the whisker, and $\tau$ the interfacial friction between whisker and matrix. ${ }^{6}$ This result is based on the assumption that the interface toughness is low enough to allow the whisker to debond at the crack tip and that load is gradually transferred to the bridging 

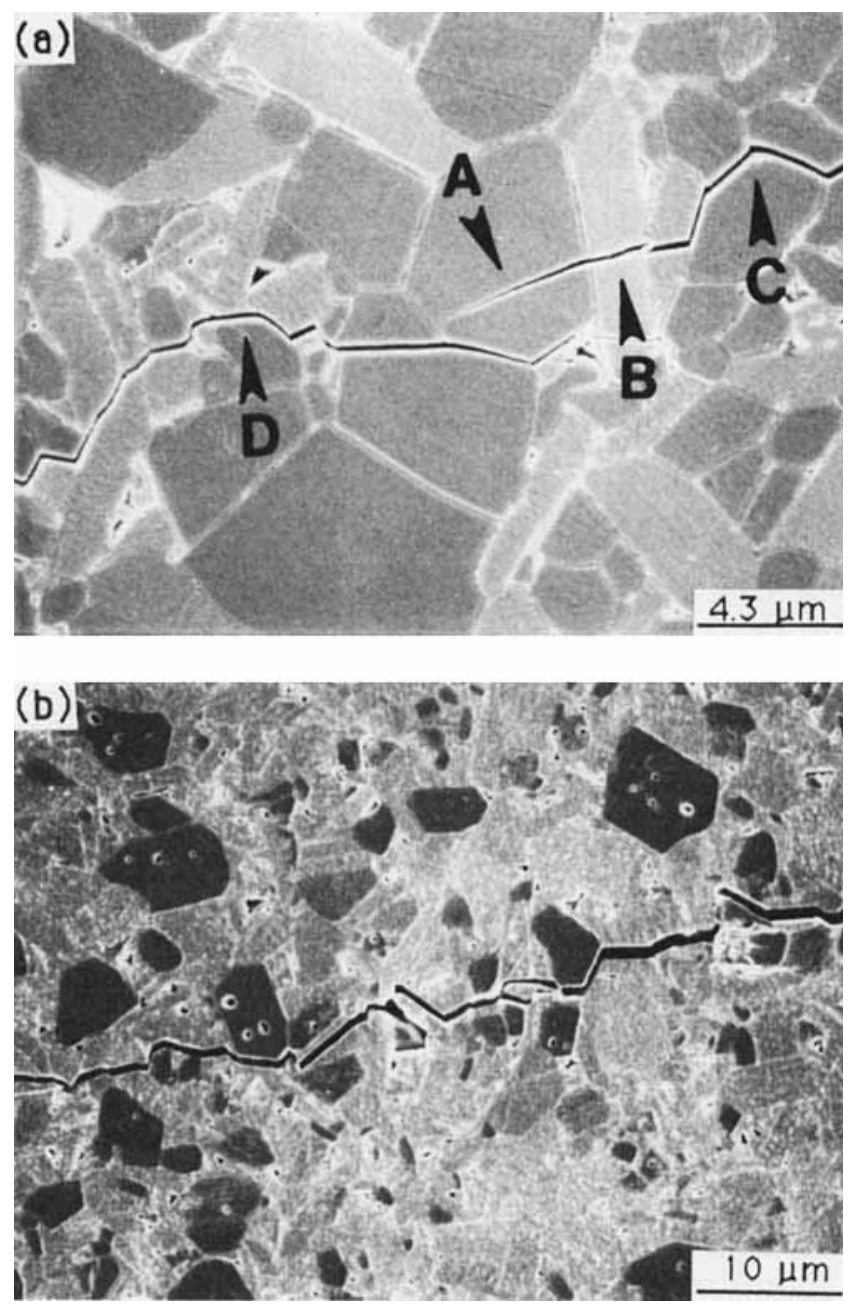

Fig. 3. Fracture microstructures of $\mathrm{MgO}$-doped $\mathrm{LaAl}_{11} \mathrm{O}_{18} / \mathrm{Al}_{2} \mathrm{O}_{3}$ : (a) $30 \mathrm{vol} \% \mathrm{LaAl}_{11} \mathrm{O}_{18}$ and (b) $60 \mathrm{vol} \% \mathrm{LaAl}_{11} \mathrm{O}_{1 \mathrm{k}}$

whiskers in the wake by friction across the whisker interface. Evidently, high-aspect-ratio aluminate platelets partially fulfill the prerequisites for a potent reinforcement by having a relatively large grain radius and a very low elastic modulus. The interface toughness also seems sufficiently low, as suggested by the frequent observations of interface debonding. In our study, more favorable interface characteristics (low roughness and friction) most likely were present given the large variety of phases, dopants, and morphologies investigated. Nevertheless, only a relatively modest energy dissipation was witnessed in all the composites prepared. We believe the reason for their failing lies in the inherently low cohesive strength of hexaluminates, which is traced to their atomic structures because of the weak bonding between spinel blocks as a result of the large spacing and few bonds therein. The latter is presumably also responsible for the low Young's modulus and hardness. (The aluminates can be considered self-reinforced by their characteristic interlocking platelike grains, resulting in the relatively high toughness of $\sim 3.2 \mathrm{MPa} \cdot \mathrm{m}^{1 / 2}$.)
Although the layer spacing and bonding are conceivably amenable to modification by judicious tailoring using crystal chemistry means, our exploration of four aluminates in this family unfortunately failed to yield further improvement in toughness despite the difference in their phase morphology. We should also mention that, at the same time this paper was presented, two other investigations on $\mathrm{Al}_{2} \mathrm{O}_{3} / \mathrm{NaMg}_{2} \mathrm{Al}_{15} \mathrm{O}_{25}$ composites were reporting essentially the same toughness value. ${ }^{7,8}$ The limit of aluminate platelet toughening thus seems quite evident.

In retrospect, it is now clear that the strength and hardness improvement reported for aluminate-modified Ce-TZP could not be due to platelet reinforcement. ${ }^{5}$ Rather, the benefit is from the interruption of $\mathrm{ZrO}_{2}$-phase connectivity which leads to suppression of autocatalytic transformation. ${ }^{9}$ This example suggests that, although aluminates are not particularly strong and tough, they might still be advantageously exploited in ceramic composite design under suitable conditions.

\section{Conclusions}

A variety of in-situ $\mathrm{Al}_{2} \mathrm{O}_{3}$ /aluminate composites have been explored with the following results:

(1) The composites can all be sintered to high density.

(2) Aluminates develop in situ a platelet morphology whose aspect ratio is dependent on the major and minor composition and the phase fraction; very elongated grains can be obtained readily in some cases.

(3) The composites exhibit a peak toughness of around 4.3 $\mathrm{MPa} \cdot \mathrm{m}^{1 / 2}$ at $30 \mathrm{vol} \%$ aluminates, representing a $50 \%$ increase over that of $\mathrm{Al}_{2} \mathrm{O}_{3}$ with only a modest reduction ( $10 \%$ ) of hardness and Young's modulus.

(4) The composites and the aluminates themselves can be considered toughened by the crack-bridging action of the aluminate platelets; however, the intrinsically low cohesive strength of these layer compounds limits the maximum toughness derivable from their reinforcement.

\section{References}

'S. Hori, H. Kaji, M. Yoshimura, and S. Sōmiya, "Deflection-Toughened Corundum-Rutile Composites," Mater. Res. Soc. Symp. Proc., 78, 283-88 (1987)

${ }^{2} \mathrm{E}$. Tani, S. Umebayashi, K. Kishi, and M. Nishijima, "Gas-Pressure Sintering of $\mathrm{Si}_{3} \mathrm{~N}_{4}$ with Concurrent Addition of $\mathrm{Al}_{2} \mathrm{O}_{3}$ and 5 wt\% Rare-Earth Oxide High Fracture Toughness $\mathrm{Si}_{3} \mathrm{~N}_{4}$ with Fiberlike Structure," Am. Ceram. Soc Bull., 65 [9] 1311 (1986).

'K. Okada, N. Otsuka, R. J. Brook, and A. J. Moulsob, "Microstructure and Fracture Toughness of Yttria-Doped Tetragonal Zirconia Polycrystal/Mullite Composites Prepared by an in Situ Method," J. Am. Ceram. Soc., 72 [12] 2369-72 (1989)

${ }^{4} K$. Tsukuma and T. Takahata, "Mechanical Property and Microstructure of TZP and TZP $/ \mathrm{Al}, \mathrm{O}_{3}$ Composites," Mater. Res. Soc. Symp. Proc., 78, 123-35 (1987)

${ }^{5}$ R. A. Cutler, R. J. Mayhew, K. M. Prettyman, and A. V. Virkar, "HighToughness $\mathrm{Ce}-\mathrm{TZP} / \mathrm{Al}_{2} \mathrm{O}_{3}$ Ceramics with Improved Hardness and Strength," J. Am. Ceram Soc, 74 [1] 179-86 (1991).

'P. F. Becher, "Microstructural Design of Toughened Ceramics," J. Am Ceram. Soc., 74 [2] 255-69(1991).

P. E. Morgan, D. B. Marshall, and J. R. Porter, "Reactive Approaches to Interface Forming in Ceramic/Ceramic Composites"; presented at the 93rd Annual Meeting of the American Ceramic Society, Cincinnati, OH, April 30 , 1991 (Ceramic Matrix Composites Symposium, Paper No. 56-SVI-91).

${ }^{8} I$. S. Lee, J. W. Ko, S. Y. Lee, and H. D. Kim, "Alumina Ceramics Rein forced with Needle-Shaped $\beta^{\prime \prime \prime}$-Alumina"; see Ref. 7, Paper No. 9-SVIP-91

${ }^{9} \mathrm{P}$. E. Reyes-Morel and I-W. Chen, "Transformation Plasticity of $\mathrm{CeO}_{2}$ Stabilized Tetragonal Zirconia Polycrystals: I, Stress Assistance and Autocatalysis," J. Am. Ceram. Soc., 71 [5] 343-53 (1988). 